\title{
Is There Only One Set of Genes for Different Abilities? A Reanalysis of the National Merit Scholarship Qualifying Test (NMSQT) Data
}

\author{
N. G. Martin, ${ }^{1}$ R. Jardine, ${ }^{2}$ and L. J. Eaves ${ }^{1}$ \\ Received 13 Feb. 1984-Final 27 Apr. 1984
}

Using the genetical analysis of covariance structure it is shown that the single factor model of Plomin and DeFries [(1979). Behav. Genet. 9:505$517]$ fails as a description of the structure of genetic covariation between the subtests of the National Merit Scholarship Qualifying Test. A genetic group factor which loads on Vocabulary, Social Studies, and English greatly improves the fit of the model. There is also a large portion of genetic variance specific to Mathematics and it is argued that the genetic variance for different abilities is far from homogeneous in its origin. The data suggest that a single dimension of mate selection or cultural inheritance accounts for a significant part of the phenotypic covariance between measures.

KEY WORDS: multivariate genetical analysis; educational achievement; twins; covariance structure; specific abilities.

\section{INTRODUCTION}

Although the "classical" approach in behavior genetics has been repeatedly criticized (e.g., Jinks and Fulker, 1970; Eaves and Eysenck, 1975; Eaves et al., 1978), it is still used by many workers. Analyses of twin data in this tradition usually do little more than demonstrate the existence of a genetical component by showing that monozygotic twins are more alike than dizygotic twins. Such inadequacies are compounded

${ }^{1}$ Department of Human Genetics, Medical College of Virginia, Box 33, Richmond, Virginia 23298-0001.

2 Department of Population Biology, Research School of Biological Sciences, Australian National University, Canberra, Australia. 
when simple correlational methods are extended to the multivariate case, as Plomin and DeFries (1979) have done in their analysis of the National Merit Scholarship Qualifying Test (NMSQT) data of Loehlin and Nichols (1976).

Any approach to the analysis of genetic data, multivariate or univariate, should strive for certain goals: (1) flexibility in specifying theoretical models and testing alternative hypotheses, (2) simplicity of generalization to other experimental designs, (3) statistical efficiency, and (4) estimation of standard errors of estimates. In the last 10 years geneticists have relied increasingly on model-fitting methods employing maximum-likelihood and related techniques to resolve ever more subtle hypotheses about the causes of human variation and family resemblance. This work has focused on issues far beyond the detection and estimation of genetic variance. Even within the classical twin study, for example, these methods have been applied to the detection and estimation of additive and nonadditive genetic effects, between- and within-family environmental effects, sibling interactions, and sex differences in the expression of genetic and environmental effects (Eaves et al., 1978).

These methods have been extended to the multivariate case and applied to data on abilities (Martin and Eaves, 1977), personality (Eaves et al., 1977; Martin et al., 1979; Clifford et al., 1981), social attitudes (Eaves and Eysenck, 1974), dermatoglyphics (Martin et al., 1982; Cantor et al., 1983), the smoking habit (Eaves and Eysenck, 1980), socioeconomic variables (Fulker, 1978), and psychomotor sensitivity to alcohol (Martin et al., 1981). Several important conclusions can be drawn from the results of these studies: (1) environmental effects within families are largely trait specific and contribute little to phenotypic covariation; (2) there are both common and specific genetic contributions to the covariance structure of multiple measures; (3) for abilities and socioeconomic variables there appear to be few trait-specific effects of assortative mating and the family environment-indeed, there is compelling evidence that the structure of between- and within-family environmental influences differs markedly; (4) sex differences in gene expression can affect both common and specific variances; (5) in some cases genetic and environmental factor loadings can be scaled so that they confirm the notion that genetic and environmental effects on multiple variables operate through a single common pathway; (6) more than one common factor can sometimes be shown to contribute to genetic covariance between measures; and (7) the contribution of additive and nonadditive genetic effects to trait covariation can be separated in some circumstances and need not show the same structure. 
These findings address directly the issues hinted at in the paper by Plomin and DeFries (1979). Using methods which have the advantage of simplicity and intuitive appeal, they conclude that the same set of genes and similarly the same set of environmental factors affect variation in all five NMSQT subtests. They do not consider (1) the contribution of specific genetic factors, preferring rather to consign these to "eigenvalues less than one"; (2) the contribution of other common factors to the genetic covariance; or (3) sex differences in the expression of genes; and (4) they make no attempt to separate the contribution of social and random environmental factors to trait covariation even though these have quite distinct etiologies and may operate on the phenotype in quite different ways.

There are two explanations of the simplicity of the findings of Plomin and DeFries: (1) the origin and structure of covariation are inherently simple and the subtleties we describe above do not pertain in this data set, or (2) their methods of analysis are not sufficiently sensitive to detect effects which are statistically significant and heuristically important.

Plomin and DeFries begin their analysis by pooling their data across sexes, without any apparent justification of this on either theoretical or empirical grounds. They then compute the matrices of cross correlations between first and second twins for each pair of variables. Twice the difference between these correlations for monozygotic (MZ) and dizygotic (DZ) twins is an estimate of "the phenotypically standardized genetic covariance matrix" or the genetic portion of the phenotypic correlation between measures. They next subtract the phenotypically standardized genetic covariance from the phenotypic correlation between the measures to yield an estimate of the total contribution of environmental factors. These matrices are then subjected to principal-axis factor analysis. All factors corresponding to eigenvalues less than one are arbitrarily discarded as having no substantive significance. The employment of this criterion for a matrix with a trace of only 2.1 means that any factor explaining less than $48 \%$ of the common genetic variance would be excluded. The findings based upon their analysis of this very large and valuable sample of ability data are remarkably simpler than those advanced in an earlier paper by Martin and Eaves (1977) analyzing a very much smaller sample but with methods which allowed statistical tests of significance and greater flexibility in specifying sources and structure of covariation. On the one hand, we must be alert to the danger of overinterpretation of inadequate data, but on the other, we must avoid the acceptance of unjustifiably simple interpretations of potentially powerful data sets. We have therefore reanalyzed the NMSQT data using methods 
which we believe can expose additional subtleties and suggest an interpretation richer than that proposed by Plomin and DeFries.

\section{DATA}

Scores for the five subtests of the NMSQT (English, Mathematics, Social Studies, Natural Science, and Vocabulary) were kindly made available to us by Dr. R. C. Nichols. Data were available for 839 same-sex twins collected in 1962 (216 MZ males, $135 \mathrm{DZ}$ males, $293 \mathrm{MZ}$ females, $195 \mathrm{DZ}$ females) and 2166 same-sex twins collected in 1965 (575 MZ males, $371 \mathrm{DZ}$ males, $725 \mathrm{MZ}$ females, $495 \mathrm{DZ}$ females). Characteristics of these samples are described by Loehlin and Nichols (1976).

\section{MULTIVARIATE ANALYSES}

We know from univariate analyses of these data (which we do not publish here since their results are completely congruous with those of the multivariate analyses below) that there are three important causes of variation, viz. $E_{1}, B$, and $V_{\mathrm{A}}$, for each subtest, at least for the 1965 sample. Here $E_{1}$ is the environmental variance within families and specific to the individual; it also includes measurement error. $B$ is a between-families component of variance in which shared environmental variation $\left(E_{2}\right)$, including cultural and parental treatment effects, is confounded with the extra additive genetic variation attributable to assortative mating. We cannot resolve the contributions of $E_{2}$ and assortative mating to $B$ without estimates of the marital correlation. $V_{\mathrm{A}}$ is the genetic variation due to the additive effects of genes in the absence of assortative mating. The contributions of these sources to variation between and within pairs of $\mathrm{MZ}$ and DZ twins are well known (e.g., Eaves et al., 1978).

Phenotypic correlations among the five subtests are shown in Table I. However, we do not know whether the three sources which contribute to variation in the individual subtests all contribute to covariation between them. A given source may contribute to the variance of individual variables but not to their covariation or may contribute to covariation between variables through one common factor and perhaps other group factors as well. This problem has beset behavior geneticists for many years and several inefficient solutions to it have been suggested. A comprehensive approach to the problem has arisen from the work of Jöreskog (1969), on maximum-likelihood factor analysis and was extended to the genetical analysis of covariance structure by Martin and Eaves (1977). Detailed explanation and further applications of the maximum-likelihood technique are given by Eaves et al. (1977), Fulker (1978), Martin et al. $(1979,1982)$, 
Table I. Correlations Among the 1962 and 1965 NMSQT Scores Separately for Males (Upper Triangle) and Females (Lower Triangle)

\begin{tabular}{|c|c|c|c|c|c|}
\hline & English & Math & $\begin{array}{l}\text { Social } \\
\text { Studies }\end{array}$ & $\begin{array}{l}\text { Natural } \\
\text { Science }\end{array}$ & Vocabulary \\
\hline \multicolumn{6}{|c|}{1962 data } \\
\hline English & - & 0.63 & 0.65 & 0.64 & 0.69 \\
\hline Math & 0.58 & - & 0.63 & 0.67 & 0.59 \\
\hline $\begin{array}{l}\text { Social } \\
\text { Studies }\end{array}$ & 0.66 & 0.58 & - & 0.70 & 0.77 \\
\hline $\begin{array}{l}\text { Natural } \\
\text { Science }\end{array}$ & 0.60 & 0.62 & 0.63 & - & 0.65 \\
\hline Vocabulary & 0.67 & 0.56 & 0.78 & 0.58 & - \\
\hline \multicolumn{6}{|c|}{1965 data } \\
\hline English & - & 0.60 & 0.66 & 0.61 & 0.71 \\
\hline Math & 0.56 & - & 0.55 & 0.61 & 0.58 \\
\hline $\begin{array}{l}\text { Social } \\
\text { Studies }\end{array}$ & 0.65 & 0.53 & - & 0.67 & 0.76 \\
\hline $\begin{array}{l}\text { Natural } \\
\text { Science }\end{array}$ & 0.61 & 0.55 & 0.68 & - & 0.65 \\
\hline Vocabulary & 0.71 & 0.55 & 0.75 & 0.65 & - \\
\hline
\end{tabular}

Clifford et al. (1981), and Cantor et al. (1983). Analyses in this paper employed either a purpose-written Fortran program which uses the NAG Mark 6 optimization routine EO4JAF (Numerical Algorithms Group, 1977) or the LISREL 4 or 5 package of Jöreskog and Sorbom (1981) as described by Cantor (1983).

The genetical analysis of covariance structure is a maximum-likelihood technique that simultaneously tests hypotheses about both sources and the structure of covariation. Just as univariate models are fitted to mean squares, the multivariate models discussed below are fitted to the between- and the within-pairs mean products matrices shown in the Appendix.

Given maximum-likelihood estimates of our parameters, the hypothesis that a less restricting model (i.e., one involving more parameters) does not significantly improve the fit can be tested by computing $\chi^{2}=$ $2\left(L_{0}-L_{1}\right)$, where $L_{1}$ is the $\log$ likelihood obtained under the restricted hypothesis $\left(H_{1}\right)$ and $L_{0}$ is the log likelihood obtained under the less demanding hypothesis $\left(H_{0}\right)$. The $H_{0}$ we use is that which assumes that as many parameters are required to explain the data as there are independent mean squares and mean products in the first place. When there are $k$ matrices $\chi^{2}$ has $\frac{1}{2} k p(p+1)-m$ df, where $m$ denotes the number of parameters estimated under $H_{1}$ and $p$ is the number of variables. 
The simplest model for each source of variation involves a single general factor causing covariation among the five scholastic abilities plus a variance component specific to each ability. This simple structural model for a source is designated $\mathrm{S}$ in Table II. The most complex model for a particular source estimates a $5 \times 5$ positive definite covariance matrix for that source. In LISREL this model is fitted most easily by recognizing that any symmetric positive definite matrix may be decomposed into the product of a triangular matrix $(T)$ and its transpose (e.g., Noble, 1969). Such a "triangular decomposition" yields, for a given source, a matrix of $(5 \times 6) / 2$ unconstrained factor loadings which may be used to generate the maximum-likelihood estimate of the corresponding covariance matrix (Cantor et al., 1983). Models allowing different combinations of unconstrained factor loadings $(T)$ and simple factor structure $(S)$ for $E_{1}, B$, and $V_{\mathrm{A}}$ allow us to determine where elaboration of factor structure is likely to be most effective. There are eight such factorial models for three sources and the results are shown in Table II.

In most cases there is significant heterogeneity of fit over sexes, suggesting that it is necessary to analyze the male and female data separately. This heterogeneity was ignored by Plomin and DeFries (1979), who analyzed the data regardless of sex but in split halves, thereby sacrificing power for replication.

The greatest reductions in chi-square are seen when the $5 \times 5$ additive genetic covariance matrices are estimated. The full decomposition of either the $E_{1}$ or the $B$ covariance matrices accounts for less of the overall covariation in NMSQT abilities than the decomposition of $V_{\mathrm{A}}$. In no case does estimation of the three completely unconstrained $E_{1}, B$, and $V_{\mathrm{A}}$ covariance matrices (TTT model) result in a significant improvement in chi-square over a model in which a simple factor structure for $E_{1}$ and $B$ and unconstrained factor loadings for $V_{\mathrm{A}}$ are allowed (SST model).

In order to summarize the gain in likelihood from fitting different combinations of factor elaborations, we have used the following convenient approach. By substituting 1 for $\mathrm{S}$ and -1 for $\mathrm{T}$ in the models in Table II, we create unweighted orthogonal contrasts for the contributions of $E_{1}, B$, and $V_{\mathrm{A}}$ to model improvement (chi-square reduction), and by appropriate multiplication of these contrasts, we obtain the contrasts for two- and three-way interactions of these effects which are shown in Table III. For example, to obtain the average effect of elaboration of the $E_{1}$ factor structure, we subtract the sum of chi-square values for models in which the $E_{1}$ structure is designated T from the sum of those in which it is designated $\mathrm{S}$ in Table $\mathrm{II}$; in the case of 1962 males this is $(79.72+$ $33.00+43.81+29.06)-(50.08+27.68+33.62+23.54)=50.67$, which is the first entry in Table III. 
Table II. Chi-Square Values for Testing Alternative Models for Covariance Structure of NMSQT Abilities for Males, Females, and Males and Females Combined (Chi-Square Values for the Heterogeneity of Fit Over Sexes Are Also Shown)

\begin{tabular}{|c|c|c|c|c|c|c|c|c|c|c|}
\hline \multirow{2}{*}{\multicolumn{2}{|c|}{ Source $a$}} & \multirow{2}{*}{$\begin{array}{l}\text { Number of } \\
\text { parameters }^{b}\end{array}$} & \multicolumn{4}{|c|}{1962} & \multicolumn{4}{|c|}{1965} \\
\hline & & & $\begin{array}{c}\text { Males } \\
(s=60)\end{array}$ & $\begin{array}{l}\text { Females } \\
(s=60)\end{array}$ & $\begin{array}{c}\text { Males \& } \\
\text { females } \\
(s=120)\end{array}$ & Heterogeneity $^{c}$ & $\begin{array}{c}\text { Males } \\
(s=60)\end{array}$ & $\begin{array}{l}\text { Females } \\
(s=60)\end{array}$ & $\begin{array}{c}\text { Males \& } \\
\text { females } \\
(s=120)\end{array}$ & Heterogeneity \\
\hline$S$ & $S \mathrm{~S}$ & 30 & $79.72 * * * *$ & $75.13 * * *$ & $206.62^{* * *}$ & $51.77 * *$ & $91.51^{* * *}$ & $82.60^{* * * *}$ & $226.78 * * *$ & $52.67^{* *}$ \\
\hline $\mathrm{S}$ & $\mathrm{S} \mathrm{T}$ & 35 & 33.00 & $48.75^{* *}$ & $138.65^{* * *}$ & $56.90^{*}$ & 33.18 & 21.16 & 104.67 & $50.33^{*}$ \\
\hline$S^{\prime}$ & $\mathrm{T} \mathrm{S}$ & 35 & $43.81^{*}$ & $51.02^{* *}$ & $151.31^{* * *}$ & $56.48^{*}$ & $47.27 * *$ & 25.58 & $120.84 * *$ & 47.99 \\
\hline$S 7$ & $\mathrm{~T} \mathrm{~T}$ & 40 & 29.06 & $43.48 * *$ & $132.72 * * *$ & $60.18^{*}$ & 23.16 & 16.61 & 101.20 & $61.43^{*}$ \\
\hline $\mathrm{T}:$ & $S \mathrm{~S}$ & 35 & $50.08^{* * *}$ & $62.40^{* * * *}$ & $161.63^{* * *}$ & 49.15 & $71.59 * * *$ & $71.09 * * *$ & $191.40^{* * *}$ & 48.72 \\
\hline $\mathrm{T}$ & $\mathrm{S} T$ & 40 & 27.68 & $38.31^{* *}$ & $127.21^{* * * *}$ & $61.22^{*}$ & 25.32 & 19.32 & 101.23 & $56.59^{*}$ \\
\hline $\mathrm{T} T$ & $\mathrm{~T} \mathrm{~S}$ & 40 & $33.62^{*}$ & $38.33^{* *}$ & $133.13 * * *$ & $61.18^{*}$ & $32.52 *$ & 23.45 & $112.35^{*}$ & $56.38^{*}$ \\
\hline $\mathrm{T} T$ & $\mathrm{~T} \mathrm{~T}$ & 45 & 23.54 & $31.47^{* *}$ & $122.03^{* * *}$ & $67.02^{*}$ & 15.50 & 15.17 & $96.75^{*}$ & $66.08^{*}$ \\
\hline
\end{tabular}

${ }^{a} \mathrm{~S}$ represents a single general factor plus specifics for a source. T represents the full-rank covariance matrix for a source (triangular decomposition).

${ }^{b}$ Degrees of freedom are the number of independent statistics $(s)$ minus the number of parameters.

c For the heterogeneity chi-square the degrees of freedom equal the number of parameters. 
Table III. Total Effect on Goodness of Fit Resulting from Elaborating the Factor Structure of $E_{1}, B$, and $V_{\mathrm{A}}$ Separately and in Combination (See Text for Explanation) ${ }^{a}$

\begin{tabular}{|c|c|c|c|c|c|c|}
\hline \multirow[b]{2}{*}{ Contrast } & \multicolumn{3}{|c|}{1962} & \multicolumn{3}{|c|}{1965} \\
\hline & Males & Females & $\begin{array}{c}\text { Males \& } \\
\text { females }\end{array}$ & Males & Females & $\begin{array}{l}\text { Males \& } \\
\text { females }\end{array}$ \\
\hline$E_{1}$ & 50.67 & 47.87 & 85.30 & 50.19 & 16.92 & 51.76 \\
\hline$B$ & 60.45 & 60.29 & 94.92 & 103.15 & 113.36 & 192.94 \\
\hline$V_{\mathrm{A}}$ & 93.95 & 64.87 & 132.08 & 145.73 & 130.46 & 247.52 \\
\hline$E_{1} \times B$ & 19.25 & -1.53 & 27.56 & 5.37 & 9.78 & 25.88 \\
\hline$E_{1} \times V_{\mathrm{A}}$ & 28.99 & 2.97 & 41.04 & 19.15 & 10.36 & 35.98 \\
\hline$B \times V_{\mathrm{A}}$ & 44.29 & 36.07 & 72.70 & 63.47 & 95.96 & 177.04 \\
\hline$E_{1} \times B \times V_{\mathrm{A}}$ & 19.65 & 1.61 & 26.06 & 4.97 & 8.98 & 27.90 \\
\hline
\end{tabular}

${ }^{a}$ Effects obtained as linear combinations of chi-square values in Table II (see text).

We do not pretend that these average differences in chi-square tabulated can be used as the basis for significance tests. However, it is now even more obvious that elaboration of the factor structure for the $V_{\mathrm{A}}$ source will produce a greater improvement in fit than any corresponding elaboration of the $E_{1}$ or $B$ structures. This is despite the fact that when all three sources of variation are present in equal proportions, the classical twin study provides more information about $E_{1}$ and $B$ than about $V_{\mathrm{A}}$ (Martin et al., 1978). We also see by the size of the $B \times V_{\mathrm{A}}$ interaction that these two effects are partially confounded, as is well known in the univariate case (Martin et al., 1978).

Referring to Table II, the model (TTT) allowing the full decomposition for $E_{1}, B$, and $V_{\mathrm{A}}$ can be used, in the separate male and female data, as an indication of the equality of total dispersion in the $M Z$ and $\mathrm{DZ}$ covariance matrices. The expected value of a chi-square with $15 \mathrm{df}$ is 15 , almost identical to the values found in the 1965 sample. In the 1962 sample they are considerably larger, and this will contribute to the failure of any models fitted to these data sets. Since chi-square is directly proportional to sample size, the greater heterogeneity in the smaller 1962 sample may be an indication that there is sampling bias in this data set.

The main message of Tables II and III, however, is that considerable improvements in fit might be obtained by appropriate elaboration of the simple genetic factor structure (S) which specifies only a general factor and specific variance components for each subtest. Inspection of Table I reveals that the highest correlations for both sexes in both years are those of Vocabulary with Social Studies and English. This suggests that there may be a group factor loading on these three subtests. Since the 
Table IV. Results of Genetic Group Factor Model with Simple Model for $E_{1}$ and $B$ Covariance (SSF Model) ${ }^{a}$

\begin{tabular}{|c|c|c|c|c|c|c|c|c|}
\hline & \multicolumn{2}{|c|}{$E_{1}$} & \multicolumn{2}{|c|}{$B$} & \multicolumn{4}{|c|}{$V_{\mathrm{A}}$} \\
\hline & \multirow[b]{2}{*}{ Factor } & \multirow[b]{2}{*}{ Specific } & \multirow[b]{2}{*}{ Factor } & \multirow[b]{2}{*}{ Specific } & \multicolumn{2}{|c|}{ Factor } & \multirow{2}{*}{\multicolumn{2}{|c|}{ Specific }} \\
\hline & & & & & I & II & & \\
\hline \multicolumn{9}{|l|}{1962 males } \\
\hline English & 8 & 19 & 47 & $7(\mathrm{~ns})^{b}$ & 19 & $\begin{array}{c}0 \\
\text { (ns) }\end{array}$ & 0 & (ns) \\
\hline Mathematics & 3 & 23 & 18 & 7 (ns) & 40 & - & 9 & * \\
\hline Social Studies & 7 & 19 & 21 & 0 (ns) & 40 & 6 & 7 & (ns) \\
\hline Natural Science & 4 & 25 & 18 & 5 (ns) & 48 & - & 0 & (ns) \\
\hline \multirow[t]{2}{*}{ Vocabulary } & 8 & 8 & 41 & 1 (ns) & 20 & 22 & - & \\
\hline & \multicolumn{8}{|c|}{$\chi_{28}^{2}=37.60(P=0.106)$} \\
\hline \multicolumn{9}{|l|}{1962 females } \\
\hline English & 4 & 18 & 20 & 3 (ns) & 35 & 6 & 14 & \\
\hline Mathematics & 6 & 22 & 23 & 0 (ns) & 29 & - & 20 & \\
\hline Social Studies & 3 & 19 & 43 & 0 (ns) & 17 & 12 & 6 & $*$ \\
\hline Natural Science & 3 & 31 & 37 & 0 (ns) & 26 & - & 3 & (ns) \\
\hline \multirow[t]{2}{*}{ Vocabulary } & 5 & 9 & 36 & 8 & 15 & 27 & - & \\
\hline & \multicolumn{8}{|c|}{$\chi_{28}^{2}=53.57(P=0.003)$} \\
\hline \multicolumn{9}{|l|}{1965 males } \\
\hline English & 5 & 21 & 33 & $0(\mathrm{~ns})$ & 25 & 4 & 12 & \\
\hline Mathematics & 3 & 26 & 25 & 0 (ns) & 28 & - & 18 & \\
\hline Social Studies & 8 & 22 & 16 & 0 (ns) & 36 & 10 & 8 & \\
\hline Natural Science & 11 & 23 & 8 & 0 (ns) & 58 & - & 0 & (ns) \\
\hline \multirow[t]{2}{*}{ Vocabulary } & 3 & 10 & 23 & $3^{* *}$ & 35 & 26 & - & \\
\hline & \multicolumn{8}{|c|}{$\chi_{28}^{2}=54.16(P=0.002)$} \\
\hline \multicolumn{9}{|l|}{1965 females } \\
\hline English & 5 & 24 & 31 & 0 (ns) & 28 & 3 & 9 & \\
\hline Mathematics & 3 & 24 & 21 & 3 (ns) & 25 & - & 24 & \\
\hline Social Studies & 7 & 23 & 14 & 7 & 44 & 5 & 0 & (ns) \\
\hline Natural Science & 6 & 27 & 7 & 0 (ns) & 60 & - & 0 & (ns) \\
\hline \multirow[t]{2}{*}{ Vocabulary } & 4 & 8 & 19 & 1 (ns) & 41 & 27 & - & \\
\hline & \multicolumn{8}{|c|}{$\chi_{28}^{2}=34.36(P=0.189)$} \\
\hline
\end{tabular}

${ }^{a}$ All variance contributions (\%) are significant at least at the $0.1 \%$ level, except as indicated.

${ }^{b}$ Not significant.

$* 0.01<P<0.05$.

** $0.001<P<0.01$.

pivotal subtest appears to be Vocabulary, no specific genetic variance is specified for this variable in order to ensure that the model is identified. This model for genetic covariance structure, consisting of a general factor, a group factor, and four specific components, is designated $F$ in Tables IV and $\mathrm{V}$. 
Table V. Results of Genetic Group Factor Model with Triangular Decomposition of $E_{1}$ and $B$ Covariance (TTF Model) ${ }^{a}$

\begin{tabular}{|c|c|c|c|c|c|}
\hline & \multirow[b]{3}{*}{$E_{1}(\mathrm{~T})$} & \multirow[b]{3}{*}{$B(\mathrm{~T})$} & \multicolumn{3}{|c|}{$\mathrm{V}_{\mathrm{A}}$} \\
\hline & & & \multicolumn{2}{|c|}{ Factor } & \multirow[b]{2}{*}{ Specific } \\
\hline & & & I & II & \\
\hline \multicolumn{6}{|l|}{1962 males } \\
\hline English & 27 & 55 & 18 & $0(\mathrm{~ns})^{b}$ & 0 (ns) \\
\hline Mathematics & 26 & 14 & 59 & - & 0 (ns) \\
\hline Social Studies & 26 & 26 & 33 & $7^{*}$ & $8^{*}$ \\
\hline Natural Science & 28 & 32 & 40 & - & 0 (ns) \\
\hline \multirow[t]{2}{*}{ Vocabulary } & 16 & 44 & 18 & 22 & - \\
\hline & \multicolumn{5}{|c|}{$\chi_{18}^{2}=24.23(P=0.148)$} \\
\hline \multicolumn{6}{|l|}{1962 females } \\
\hline English & 22 & 26 & 47 & $1(\mathrm{~ns})$ & 4 (ns) \\
\hline Mathematics & 30 & 30 & 16 & - & 24 \\
\hline Social Studies & 22 & 41 & 31 & 2 (ns) & 4 (ns) \\
\hline Natural Science & 35 & 45 & 20 & - & 0 (ns) \\
\hline \multirow[t]{2}{*}{ Vocabulary } & 14 & 51 & 23 & $13^{\text {se*te }}$ & - \\
\hline & \multicolumn{5}{|c|}{$\chi_{18}^{2}=36.35(P=0.006)$} \\
\hline \multicolumn{6}{|l|}{1965 males } \\
\hline English & 26 & 29 & 41 & 1 (ns) & 3 (ns) \\
\hline Mathematics & 29 & 30 & 24 & - & 17 \\
\hline Social Studies & 30 & 24 & 31 & $6 * *$ & 9 \\
\hline Natural Science & 35 & 26 & 39 & - & 0 (ns) \\
\hline \multirow[t]{2}{*}{ Vocabulary } & 13 & 37 & 28 & 22 & - \\
\hline & \multicolumn{5}{|c|}{$\chi_{18}^{2}=21.74(P=0.244)$} \\
\hline \multicolumn{6}{|l|}{1965 females } \\
\hline English & 28 & 28 & 30 & $3^{*}$ & 11 \\
\hline Mathematics & 27 & 22 & 29 & - & 22 \\
\hline Social Studies & 30 & 34 & 33 & 2 (ns) & 1 (ns) \\
\hline Natural Science & 33 & 12 & 55 & - & 0 (ns) \\
\hline \multirow[t]{2}{*}{ Vocabulary } & 11 & 24 & 42 & 23 & - \\
\hline & \multicolumn{5}{|c|}{$\chi_{18}^{2}=16.70(P=0.544)$} \\
\hline
\end{tabular}

${ }^{a}$ All variance contributions $(\%)$ are significant at least at the $0.1 \%$ level, except as indicated.

${ }^{b}$ Not significant.

$* 0.01<P<0.05$.

*** $0.001 P<0.01$.

Results of fitting this model in conjunction with the simple model for $E_{1}$ and $B$ sources (which we shall term the SSF model) are shown in Table IV. Notice that the table contains percentages of variance and not factor loadings, so that the contributions of factor and specific sources may be readily assessed. The square roots of these proportions are equiv- 
alent to the phenotypically standardized factor loadings used by Plomin and DeFries. We judge its fit by comparison with the SSS model in Table II. For both sexes in both years we observe a great improvement in fit for the two additional parameters estimated and this appears to be due to the allowance in the model for genetic group factor covariation among Vocabulary, Social Studies, and, to a lesser extent, English. So large is the improvement in 1962 males and 1965 females that the SSF model actually fits the data. While this is always the goal of covariance structure analysis, it is not often realized, except in the most unparsimonious models, particularly when the degrees of freedom are large (as they are for the 1965 females) (Martin et al., 1979; Jöreskog and Sorbom, 1981). Three other features which we note here but reserve comment on for discussion below are the negligible $B$-specific components of variance, the large specific genetic variance for Mathematics, and the fact that all genetic variance for Natural Science appears to be accounted for by the common factor.

It could be argued against the SSF model that elaboration of the factor structure for any of the three sources of covariation might produce an equally good improvement in fit. A crucial test of this objection is to fit the same genetic group factor model $(F)$ at the same time as a triangular decomposition for $E_{1}$ and $B$, which should remove all covariation due to these two sources. If an improvement in fit of this TTF model is observed over the TTS model in Table II, we may take this as unequivocal evidence of covariation due to a genetic group factor over and above that due to the genetic common factor.

Results of the TTF model are shown in Table V. In all cases except 1962 females the model fits and a significant improvement in fit is observed over the TTS model, and in no case is the fit significantly worse than that of the fully determined TTT model. In Table V $E_{1}(\mathrm{~T})$ and $B(\mathrm{~T})$ refer to the total amount of variation due to these sources, as estimated by their triangular decompositions. Since there is a large amount of confounding of $V_{\mathrm{A}}$ with the $B$ and even with the $E_{1}$ sources of covariation (Table III), it is not surprising that many of the genetic factor loadings are reduced in the TTF model over the SSF model. Nevertheless, significant loadings on the genetic group factor are observed for at least two subtests in all groups except for 1962 females. There is clear evidence of group factor covariation between Vocabulary and Social Studies in both the male samples.

\section{DISCUSSION}

Our multivariate analyses have demonstrated that the simple environmental and genetic factor model proposed by Plomin and DeFries 
(1979) ignores many of the subleties in the causes of covariation between NMSQT subtest scores. As with other investigations of the covariance structure of multiple abilities and socioeconomic variables, we find that most of the environmental variation within families is trait specific. This finding is exactly what might be expected if developmental accidents and errors of measurement were not generalized in their effects on cognitive performance.

In contrast, the effects of genes are both common and specific. Our analysis suggests that the contribution of genetic factors to the correlation of abilities is more complex than that postulated in the single-common factor model of Plomin and Defries. It is true that the first common factor accounts for most of the genetic covariation, but a model with a general genetic factor, an independent group factor loading on Vocabulary, Social Studies, and English, and specific genetic variance for all except Vocabulary gives a much better fit to both sexes in both years. This is true whether improvement is judged against a simple structure model for $E_{1}$ and $B$ or a triangular decomposition of covariation for these two sources.

The $V_{\mathrm{A}}$ matrix reflects only the effects of genes whose associations are broken by segregation of alleles and Mendelian assortment of loci. Insofar as group and specific factors are required to account for this covariation between relatives, it must be conceded that there is a genetic foundation to the psychologists' claim to differentiate the various aspects of cognitive performance by employing multiple ability measures. There is, however, a major distinction between what can be achieved technically and what matters biologically or socially. It is striking that the B matrix is virtually of rank 1. This finding has important implications for our understanding of the biological and social significance of specific abilities. Eaves et al. (1984) have proved that B will have unit rank if assortative mating and/or cultural inheritance are not based on specific abilities or on groups of abilities but on a single latent variable to which each of the specific abilities contributes linearly and additively. This dimension could be general ability but could equally be a major educational or socioeconomic variable to which the specific abilities contribute. Thus, the multivariate data on cognitive abilities suggest that biological and sociological significance does not coincide with the specific abilities resolved by particular tests. Indeed, it is probably the case that genetic effects can be found which are unique to almost any measure, however trivial (see Eaves and Young 1981). It is only when we look at how those genetic and environmental effects relate to the biologically important processes of mate selection and cultural inheritance that the task of multivariate genetic analysis becomes anything more than "fact finding." Our analysis and earlier similar analyses (Martin and Eaves, 1977; Fulker, 1978) strongly 
point to composite variables as those in which spouses and parents invest most of their effort.

It should be noted that the important distinctions made above between the structure of covariation due to $E_{1}$ and that due to $B$ are entirely missing in the interpretation of Plomin and DeFries. They treat environmental covariation as a single entity and ignore the possibility that its individual and shared components may have quite different structures; nor do they consider that assortative mating, which is known to occur for ability traits, might contribute genetic covariation to $B$ which is of a structure different from that detected in the $V_{\mathrm{A}}$ component.

Other outstanding and consistent features of the results are the $a b$ sence of any genetic variance for Natural Science other than that due to the general factor and the large amount of specific genetic variance for Mathematics in all groups (except possibly 1962 males). There is a large amount of group factor genetic variance for Vocabulary which covaries with Social Studies and, to a lesser extent, English. We also observe that $E_{1}$ variance is consistently much smaller than for any other subtest. We must conclude, then, that although there is common factor genetic variance for all five subtests, there is anything but homogeneity between them in either the origin or the relative importance of genetic and environmental variance; nor is there homogeneity between males and females in the causes of covariation (Table II), although this was ignored by Plomin and DeFries. It is most unfortunate that opposite-sex twins were discarded from the original NMSQT twin sample, thus precluding any investigation of possible sex-dependent effects operating in these abilities (Eaves, 1977).

One difficulty in studying individual differences in scholastic achievement is to obtain a sample which represents the full range of ability in the cohort. This problem of selection bias may have caused the discrepancy between the results for the 1962 and those for the 1965 samples. We speculate that some of the aberrant features of the 1962 results arise from the great potential for unsystematic bias in the selection of that sample which did not pertain in 1965. It is possible, however, at least in the univariate case, to make allowance for sampling bias that is systematic, as in the case of truncation selection. Although our analysis of the 1965 data suggests that within-families environment is more important than between-families differences, we have shown elsewhere (Martin and Wilson, 1982) that this partition is reversed if allowance is made for the fact that candidates for the NMSQT were probably drawn from only the most able $16 \%$ or so of the cohort (Loehlin and Nichols, 1976).

The advantages of our approach are clear. There is considerable flexibility in the specification and testing of models for trait covariation 
and one can subject these hypotheses to rigorous tests. Our analysis shows that the methods described by Plomin and DeFries leave significant aspects of the data unresolved. We believe that these problems are inherent in any attempt to extend the classical twin method to the multivariate case in the absence of explicit genetic and structural theory and a rigorous strategy for hypothesis testing.

\section{APPENDIX \\ Mean Products Matrices for the Five NMSQT Subtests for the 1962 Sample}

English

Mathematics

Social Studies

Natural Science

Vocabulary
MZ males between pairs, 215 df

\begin{tabular}{lrrrr}
41.20 & 35.44 & 31.51 & 36.00 & 32.55 \\
\hline 6.75 & 66.62 & 38.39 & 45.97 & 34.96 \\
1.62 & 10.01 & 45.40 & 39.56 & 37.21 \\
2.14 & 1.03 & 6.59 & 55.75 & 35.03 \\
0.78 & 1.59 & 1.67 & 9.59 & 46.71 \\
1.97 & 1.19 & 1.85 & 1.39 & 3.87
\end{tabular}

$\mathrm{MZ}$ males within pairs, $216 \mathrm{df}$

DZ males between pairs, $134 \mathrm{df}$

\begin{tabular}{lrrrr}
36.78 & 30.33 & 24.22 & 27.08 & 25.25 \\
\hline 7.84 & 49.76 & 29.24 & 32.96 & 28.04 \\
6.76 & 20.52 & 35.08 & 30.62 & 29.10 \\
4.11 & 8.13 & 13.69 & 47.00 & 28.68 \\
5.31 & 10.45 & 6.95 & 14.75 & 34.77 \\
3.53 & 5.79 & 6.66 & 5.85 & 8.48
\end{tabular}

DZ males within pairs, 135 df

MZ females between pairs, $292 \mathrm{df}$

\begin{tabular}{lrrrr}
36.86 & 31.32 & 27.39 & 29.32 & 27.81 \\
\cline { 1 - 1 } 4.54 & 59.43 & 32.70 & 38.86 & 31.36 \\
1.32 & 9.96 & 39.32 & 32.30 & 34.49 \\
0.52 & 1.86 & 4.69 & 52.49 & 28.87 \\
0.60 & 2.28 & 0.47 & 11.16 & 43.71 \\
1.17 & 1.22 & 1.03 & 1.03 & 3.07
\end{tabular}

MZ females within pairs, $293 \mathrm{df}$

DZ females between pairs, $194 \mathrm{df}$

\begin{tabular}{lrrrr}
28.72 & 24.05 & 22.54 & 26.11 & 22.79 \\
\hline 9.51 & 55.79 & 26.46 & 35.45 & 25.90 \\
5.36 & 20.65 & 35.26 & 30.92 & 28.76 \\
5.04 & 4.56 & 9.63 & 46.00 & 28.31 \\
4.06 & 5.93 & 3.38 & 13.88 & 34.11 \\
4.19 & 4.87 & 4.38 & 3.72 & 6.89
\end{tabular}

DZ females within pairs, 195 df 


\section{Mean Products Matrices for the Five NMSQT Subtests for the 1965 Sample}

\begin{tabular}{lrrrr} 
& & \multicolumn{3}{c}{ MZ males between pairs, 574 df } \\
40.30 & 24.76 & 30.57 & 25.91 & 33.12 \\
\hline 6.29 & 36.63 & 25.15 & 25.28 & 25.89 \\
1.14 & 6.56 & 44.64 & 30.37 & 37.09 \\
1.38 & 0.87 & 8.13 & 38.19 & 29.78 \\
1.52 & 1.44 & 2.62 & 8.63 & 47.96 \\
0.99 & 1.04 & 1.45 & 1.40 & 3.37
\end{tabular}

$\mathrm{MZ}$ males within pairs, $575 \mathrm{df}$

DZ males between pairs, $370 \mathrm{df}$

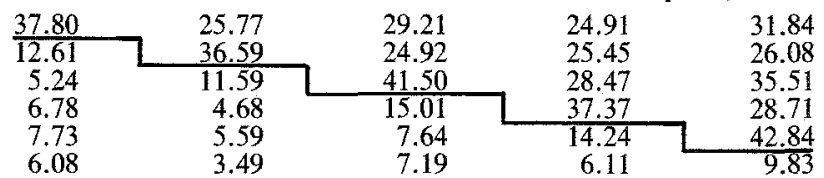

DZ males within pairs, $371 \mathrm{df}$

MZ females between pairs, $724 \mathrm{df}$

\begin{tabular}{lrrrr}
37.99 & 23.98 & 28.31 & 26.75 & 31.65 \\
\hline 6.36 & 239.63 & 23.43 & 24.53 & 24.18 \\
0.86 & 6.61 & 41.73 & 30.95 & 35.85 \\
1.39 & 1.32 & 7.80 & 41.41 & 30.53 \\
1.22 & 0.86 & 1.70 & 8.78 & 47.52 \\
0.96 & 0.87 & 1.29 & 1.09 & 2.99
\end{tabular}

MZ females within pairs, $725 \mathrm{df}$

DZ females between pairs, $494 \mathrm{df}$

\begin{tabular}{|c|c|c|c|c|}
\hline 36.07 & 24.69 & 29.52 & 25.60 & 30.96 \\
\hline 11.39 & 38.99 & 25.25 & 24.32 & 26.20 \\
\hline 4.51 & 13.36 & 44.03 & 31.53 & 35.58 \\
\hline 5.74 & 5.13 & 13.01 & 38.52 & 29.85 \\
\hline 5.94 & 6.46 & 7.97 & 15.64 & 43.45 \\
\hline 6.37 & 5.63 & 7.34 & 7.84 & 11.68 \\
\hline
\end{tabular}

DZ females within pairs, $495 \mathrm{df}$

\section{ACKNOWLEDGMENTS}

We are grateful to Dr. R. C. Nichols for making the NMSQT data available to us, to Dr. D. Jarjoura, who carried out some of the preliminary analyses, and to Drs. T. Speed and H. Kiiveri, who advised us on the identifiability problem. We thank Drs. A. C. Heath and W. E. Nance for helpful comments on the manuscript.

\section{REFERENCES}

Cantor, R. M. (1983). A multivariate genetic analysis of ridge count data from the offspring of monozygotic twins. Acta Genet. Med. Gemellol. 32:161-208.

Cantor, R. M., Nance, W. E., Eaves, L. J., Winter, P. M., and Blanchard, M. M. (1983). Analysis of the covariance structure of digital ridge counts in the offspring of monozygotic twins. Genetics 103:495-512. 
Clifford, C. A., Fulker, D. W., and Murray, R. M. (1981). A genetic and environmental analysis of obsessionality in normal twins. Proceedings of the Third International Congress on Twin Studies, Alan R. Liss, New York, pp. 163-168.

Eaves, L. J. (1977). Inferring the causes of human variation. J. Roy. Stat. Soc. A 140:324355.

Eaves, L. J., and Eysenck, H. J. (1974). Genetics and the development of social attitudes. Nature 249:288-289.

Eaves, L. J., and Eysenck, H. J. (1975). The nature of extraversion: A genetical analysis. J. Personal. Soc. Psychol. 32:102-112.

Eaves, L. J., and Eysenck, H. J. (1980). The relationship between smoking and personality. In Eysenck, H. J. (ed.), The Causes and Effects of Smoking, Maurice Temple Smith, London, Chap. 6.

Eaves, L. J., and Young, P. A. (1981). Genetical theory and personality differences. In Lynn, R. (ed.), Dimensions of Personality, Pergamon Press, New York.

Eaves, L. J., Martin, N. G., and Eysenck, S. B. G. (1977). An application of the analysis of covariance structures to the psychogenetical study of impulsiveness. Br. J. Math. Stat. Psychol. 30:185-197.

Eaves, L. J., Last, K., Young, P. A., and Martin, N. G. (1978). Model-fitting approaches to the analysis of human behaviour. Heredity 41:249-320.

Eaves, L. J., Heath, A. C., and Martin, N. G. (1984). A note on the generalized effects of assortative mating. Behav. Genet. 14:371-376.

Fulker, D. W. (1978). Multivariate extensions of a biometrical model of twin data. Proceedings of the Second International Congress on Twin Studies, Alan R. Liss, New York, pp. 217-236.

Jinks, J. L., and Fulker, D. W. (1970). Comparison of the biometrical genetical, MAVA, and classical approaches to the analysis of human behaviour. Psychol. Bull. 73:311348.

Jöreskog, K. G. (1969). A general approach to confirmatory maximum likelihood factor analysis. Psychometrika 34:183-202.

Jöreskog, K. G., and Sorbom, D. (1981). LISREL V: Analysis of linear structural relationships by maximum likelihood and least squares methods. International Educational Services, Chicago.

Loehlin, J. C., and Nichols, R. C. (1976). Heredity, Environment and Personality, University of Texas Press, Austin.

Martin, N. G., and Eaves, L. J. (1977). The genetical analysis of covariance structure. Heredity 38:79-95.

Martin, N. G., Eaves, L. J., Kearsey, M. J., and Davies, P. (1978). The power of the classical twin study. Heredity 40:97-116.

Martin, N. G., Eaves, L. J., and Fulker, D. W. (1979). The genetical relationship of impulsiveness and sensation seeking to Eysenck's personality dimensions. Acta Genet. Med. Gernellol. 28:197-210.

Martin, N. G., Eaves, L. J., and Loesch, D. Z. (1982). A genetical analysis of covariation between finger ridge counts. Ann. Hum. Biol. 9:539-552.

Martin, N. G., Gibson, J. B., Oakeshott, J. G., Wilks, A. V., Starmer, G. A., Craig, J., and Perl, J. (1981). A twin study of psychomotor performance during alcohol intoxication: Early results. Twin Research 3: Epidemiological and Clinical Studies, Alan R. Liss, New York, pp. 89-96.

Martin, N. G., and Wilson, S. R. (1982). Bias in the estimation of heritability from truncated samples of twins. Behav. Genet. 12:467-472.

Numerical Algorithms Group (1978). NAG Fortran Library Manual, Mark 6, NAG Central Office, Oxford, U.K.

Noble, B. (1969). Applied Linear Algebra, Prentice-Hall, New York.

Plomin, R., and DeFries, J. C. (1979). Multivariate behavioural genetic analysis of twin data on scholastic abilities. Behav. Genet. 9:505-517. 